\title{
Spatial clustering of loggerhead sea turtles in coastal waters of the NW Atlantic Ocean: implications for management surveys
}

\author{
Michael D. Arendt ${ }^{1, *}$, Jessica Boynton ${ }^{1}$, Jeffrey A. Schwenter ${ }^{1}$, Julia I. Byrd ${ }^{1}$, \\ Albert L. Segars ${ }^{1}$, J. David Whitaker ${ }^{1}$, Lindsey Parker ${ }^{2}$, David W. Owens ${ }^{3}$, \\ Gaëlle M. Blanvillain ${ }^{3}$, Joseph M. Quattro ${ }^{4}$, Mark A. Roberts ${ }^{4}$ \\ ${ }^{1}$ Marine Resources Division, South Carolina Department of Natural Resources, 217 Fort Johnson Road, Charleston, \\ South Carolina 29412, USA \\ ${ }^{2}$ Marine Extension Service, University of Georgia, 715 Bay Street, Brunswick, Georgia 31520, USA \\ ${ }^{3}$ Grice Marine Laboratory, College of Charleston, 205 Fort Johnson Road, Charleston, South Carolina 29412, USA \\ ${ }^{4}$ Department of Biological Sciences, University of South Carolina, 715 Sumter Street, Columbia, South Carolina 29208, USA
}

\begin{abstract}
A regional (29.9 to $33.1^{\circ} \mathrm{N}$ ) trawl survey was conducted from 2000 to 2003 and 2008 to 2011 to assess the relative abundance of sea turtles on an important foraging ground. A total of 1461 loggerhead sea turtles Caretta caretta were captured in $23 \%$ of 4756 trawling events randomly conducted in coastal waters 4 to $17 \mathrm{~m}$ deep. Seventy-five percent of positive catches consisted of the capture of a single loggerhead sea turtle with up to 10 loggerhead sea turtles captured per event. Loggerhead sea turtle capture locations were significantly clustered throughout the survey area. Nine percent of sampling events (446) occurred in spatial 'hotspots' and captured $23 \%$ of loggerhead sea turtles (339). Four percent of sampling events (193) occurred in spatial 'coldspots' and captured $1 \%$ of loggerhead sea turtles (18). The probability of loggerhead sea turtle capture in any given trawling event was significantly greater following the capture of a loggerhead sea turtle in the previous trawling event, but twice as great within hotspots (0.53) as elsewhere $(0.25)$. Hot- and coldspots were not explained by carapace length, turtle sex, genetic haplotype, 25 biotic and abiotic attributes associated with trawling events, or bycatch co-occurrence. Because of the universal application of these standardized and relatively easy to compute metrics, we recommend their inclusion in future studies to account for discrepancies in spatial distribution patterns.
\end{abstract}

KEY WORDS: Loggerhead sea turtle $\cdot$ Caretta caretta $\cdot$ Moran's index - Hotspot analysis · Cluster analysis · NW Atlantic Ocean

\section{INTRODUCTION}

Ecological comprehension of all organisms is contingent upon reliable documentation of their geographic distribution at a variety of temporal and spatial scales. Knowledge of historical distribution enables assessment of range reductions (Loughlin et al. 1984) and range expansions (Hill et al. 1999) critical precursors for effective conservation and management. A priori understanding of spatial distributions is also crucial for conducting ad hoc impact assessments following catastrophic events such as oil spills (Smith \& Simpson 1995) and epizootic outbreaks (Forcada et al. 1994). Subsequent to knowing 
where species occur, the more important question of why they occur there can begin to be addressed. For example, in multiple ocean basins, studies reveal that cetaceans congregate in coastal areas associated with high primary productivity as opposed to further from shore (Smith et al. 1986, Parra et al. 2006). The importance of mesoscale currents and productivity patches is also reported for sea turtles in oceanic habitats worldwide (Revelles et al. 2007, Mansfield et al. 2009, Kobayashi et al. 2011).

Given a tendency towards patchy rather than random organism distributions (Pennington 1996), it is imperative that monitoring surveys account for parameters that influence their subject's spatial distribution. Marsh \& Sinclair (1989) emphasize examining such influences with respect to whether an organism is likely to be present at the time of sampling (and therefore available to be documented), as well as whether available individuals are able to be perceived as being present. The latter concern is referred to as 'detectability' (Anderson 2001) and is most applicable to visual surveys that do not actually capture individuals; however, the related concern of catchability is applicable to surveys that employ physical capture methods, such as trawl surveys (Butler et al. 1987). In theory, random sampling should neutralize spatial distribution bias, given an equal chance of sampling areas with both high and low probability of occurrence. As such, if a survey is conducted during an appropriate temporal window, random sampling should provide the best estimate of actual spatial distributions and relative abundance. However, because patchy distributions depress means and elevate variance (Pennington 1996), random sampling may exacerbate this problem. A variety of statistical techniques are available for analyzing zero dispersed data sets (Maunder \& Punt 2004), but accounting for a substantial proportion of their extensive variance represents a greater challenge.

Given historical emphasis on fishery-dependent monitoring, few randomly generated data sets regarding the spatial distribution of free-ranging sea turtles exist. Sea turtle bycatch occurs as 'rare events' in both artisanal (Alfaro-Shigueto et al. 2008) and industrial commercial fisheries (Pradhan \& Leung 2006), but nevertheless remains a concern given the cumulative global bycatch (Wallace et al. 2010). Influences on sea turtle catch rates in commercial fisheries have been evaluated for both oceanic (Pradhan \& Leung 2006, Gilman et al. 2007, Gardner et al. 2008, Lewison et al. 2009, Petersen et al. 2009, Pons et al. 2010, Ferreira et al. 2011) and continental shelf habitats (Murray 2011, Warden 2011). Sea turtle catches are serially correlated across space and time (Gilman et al. 2007, Gardner et al. 2008, Lewison et al. 2009), indicative of aggregations. However, even with frequent sampling of these aggregations, due to the non-random nature of commercial fisheries, less than a third of data set variance is explained by consistently important parameters such as thermohaline boundaries, water depth, and latitude (Pradhan \& Leung 2006, Pons et al. 2010, Ferreira et al. 2011, Murray 2011, Warden 2011). Consequently, considerable work remains to account for most of the variance in sea turtle distribution data sets.

Since the early 1980 s, increased catch rates for loggerhead sea turtles Caretta caretta in coastal waters of the SE USA have been documented from monitoring index stations (Ehrhart et al. 2007, Arendt et al. 2012a) and commercial fishers (Epperly et al. 2007). Increased sea turtle abundance has correlated with conservation efforts on land and in the water over the same period (Frazer 1992, Watson et al. 2005, Marcovaldi \& Chaloupka 2007). Despite their effectiveness, however, in-water conservation measures do not eliminate all sea turtle interactions, and their benefits may still require decades to become apparent (Crowder et al. 1994). Because anthropogenic interactions with sea turtles could increase in the future concurrent with increased sea turtle abundance, understanding the temporal and spatial distribution patterns of sea turtles is critical to mitigating negative outcomes. Coastal waters in the SE USA are a prime example of a high interaction risk area between competing interests. Specifically, large juvenile sea turtles of great conservation value (Crouse et al. 1987) exhibit seasonal fidelity to the same near-shore coastal waters (Arendt et al. 2012b) targeted by economically important trawl fisheries (NOAA FishWatch, www.fishwatch.gov/wild_seafood/in_the_us. $\mathrm{htm}$ ) which, prior to mandated use of turtle excluder devices (TEDs), were once blamed for sea turtle demise (NRC 1990).

Since 2000, the National Marine Fisheries Service (NMFS) has funded a regional trawl survey to randomly sample coastal waters in the SE USA to assess sea turtle health and relative abundance. Here we examine spatial distribution trends for loggerhead sea turtles captured (or not captured) during 2 sampling periods of $4 \mathrm{yr}$ each between 2000 and 2011. The first objective was to test the null hypothesis of random spatial distribution of loggerhead sea turtles within the study area. The second objective was to test the null hypothesis of no serial correlation in capture frequency of loggerhead sea turtles. The third objective was to statistically evaluate the influences 
of demographic parameters (size, sex, and natal origin) and a suite of biotic and abiotic parameters on the observed spatial distribution patterns of loggerhead sea turtles.

\section{MATERIALS AND METHODS}

\section{Trawling overview}

Trawling for Caretta caretta was completed by research and contracted commercial vessels $\sim 23 \mathrm{~m}$ in length towing paired $18.3 \mathrm{~m}$ (head rope) NMFS turtle nets characterized by 4 seams, 4 legs, 2 bridles, and a net body with a $10.2 \mathrm{~cm}$ bar and $20.3 \mathrm{~cm}$ stretch mesh. Trawl duration (bottom time) was $30 \mathrm{~min}$ in 2000 to 2003 and 2011, but was reduced to $20 \mathrm{~min}$ in 2008 to 2010 per NMFS Office of Protected Resources. Trawling was completed between May and August in 2000 and 2008, but from May through July in all other years.

Trawling occurred from Winyah Bay, South Carolina $\left(33.1^{\circ} \mathrm{N}\right)$, to St. Augustine, Florida $\left(29.9^{\circ} \mathrm{N}\right.$; Fig. 1), USA, in waters 4 to $14 \mathrm{~m}$ deep. Within the survey area, 4 sub-regions were recognized based on sampling strata established by the Southeastern Area Monitoring and Assessment Program (SEAMAP): St. Augustine to Brunswick, Georgia $\left(31.1^{\circ} \mathrm{N}\right)$; Brunswick to Savannah, Georgia $\left(32.0^{\circ} \mathrm{N}\right)$; Savannah to Charleston, South Carolina $\left(32.7^{\circ} \mathrm{N}\right)$; and Charleston to Winyah Bay.

Trawling occurred at locations selected from a data set of 1500 coordinate pairs representing the center of $3.4 \mathrm{~km}^{2}$ grids within the survey area. Except during August 2008 (69 trawling events, 1\%), when repeat trawling targeted stations associated with high capture rates, and May through July 2010 (480 trawling events, $10 \%$ ), when repeat sampling was conducted at a sub-set of randomly selected stations, the annual station list was randomly selected from the entire station universe. The proportion of capture and non-capture events was not significantly different $\left(\chi_{2}^{2}=1.4, \mathrm{p}=0.507\right)$ among these 3 data sets; thus, data were pooled to maximize effort replication and turtle captures for subsequent analyses.

\section{Sea turtle capture and general processing}

Captured loggerhead sea turtles were removed from nets and examined for general health status and injuries before being scanned for pre-existing tags. Unique identification numbers were assigned when each sea turtle was first encountered, and used again to denote recapture events. A suite of morphometric measurements were collected, but here we only report minimum straight-line carapace length $\left(\mathrm{SCL}_{\min }, \mathrm{cm}\right)$ recorded using tree calipers. Loggerhead sea turtles were tagged externally (2 Inconel 681 flipper tags provided by the Archie Carr Center for Sea Turtle Research, Gainesville, Florida) and internally (passive integrated transponder tag, TX1406L, $125 \mathrm{kHz}$, Biomark) prior to release.

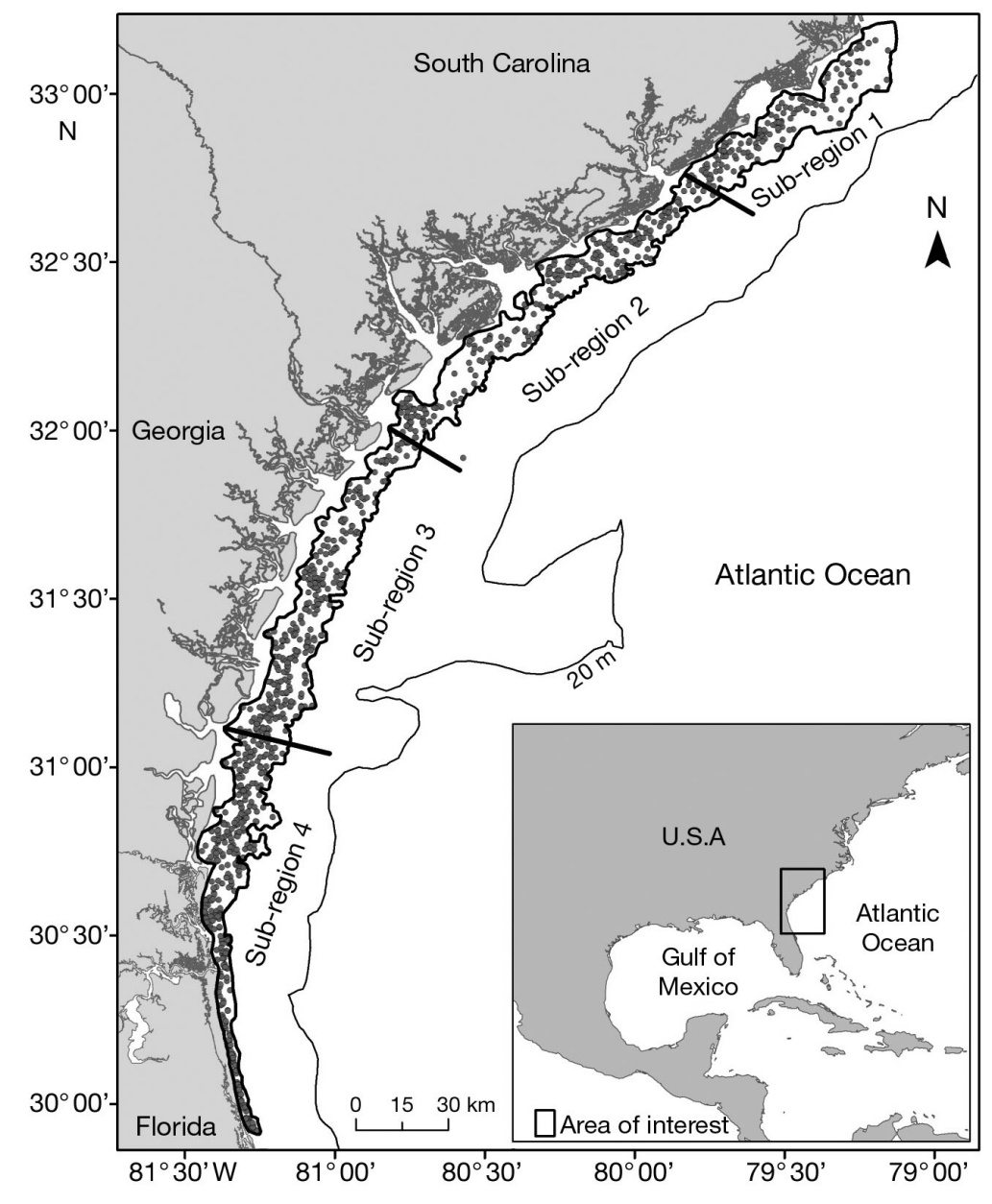

Fig. 1. Caretta caretta. Spatial distribution of 1461 loggerhead sea turtle captures in 4756 trawling events conducted in coastal waters from Winyah Bay, South Carolina $\left(33.1^{\circ} \mathrm{N}\right)$, to St. Augustine, Florida $\left(29.9^{\circ} \mathrm{N}\right)$, USA, in the summers from 2000 to 2003 and 2008 to 2011. Thick black line: trawl survey boundaries; thin black line: $20 \mathrm{~m}$ depth contour; grey dots: starting points of trawls resulting in captures 
Blood samples were collected from the dorsal cervical sinus (Owens \& Ruiz 1980) of each loggerhead sea turtle using a 21 gauge, $3.5 \mathrm{~cm}$ needle to assess sex and genetic origin, which enabled evaluation of spatial distribution with respect to critical demographic parameters. Blood samples for sex determination were collected in vacutainer tubes containing sodium heparin and centrifuged, and serum was stored in liquid nitrogen until transfer to a shorebased $-80^{\circ} \mathrm{C}$ freezer.

In the laboratory, serum testosterone concentrations were measured via radioimmunoassay, as described in Braun-McNeill et al. (2007) and considered reliable at water temperatures $>23^{\circ} \mathrm{C}$; in the present study loggerhead sea turtles were captured at mean $( \pm \mathrm{SD})$ surface water temperatures of $27.1 \pm$ $1.6^{\circ} \mathrm{C}$. Through 2003, loggerheads with plasma testosterone concentrations $<200 \mathrm{pg} \mathrm{ml}^{-1}$ were identified as female, between 200 and $300 \mathrm{pg} \mathrm{ml}^{-1}$ as undetermined, and $>300 \mathrm{pg} \mathrm{ml}^{-1}$ as male. Discontinuation of some of the original reagents for the assay in 2004 necessitated that this scale be adjusted after validation between new and old reagents. As such, since 2004, sex has been assigned as follows: female $\left(<400 \mathrm{pg} \mathrm{ml}^{-1}\right.$ ), undetermined (400 to $500 \mathrm{pg} \mathrm{ml}^{-1}$ ), and male (>500 pg ml-1). Furthermore, sex was cautiously assigned for loggerhead sea turtles $\geq 75.1 \mathrm{~cm} \mathrm{SCL}_{\min }$ with short tails, as pubescent females can be associated with elevated testosterone concentrations (D. W. Owens pers. obs.). Whole blood samples $(0.5 \mathrm{ml})$ were prepped with a lysis buffer solution $(0.8 \mathrm{ml})$ and stored at room temperature prior to sequencing a 378 base pair fragment of the mitochondrial DNA (mtDNA) control region as described by Roberts et al. (2005) to determine genetic haplotypes (Bowen et al. 2004).

\section{Non-random distribution}

The first null hypothesis of random distribution was statistically tested using Moran's index (ArcGIS ArcInfo Desktop 10.0; ESRI), which measures feature similarity based on both the feature locations ( $x$ - and $y$-coordinates) and feature attribute values. In the present study, feature locations were the trawling event start latitude and longitude values, and the feature attribute values were the loggerhead sea turtle captures per unit effort (trawl duration in minutes) overall and within the 4 sub-regions. With any set of feature locations, and a single attribute, Moran's index measures whether the location pattern is clustered, dispersed, or random based on that attribute.
The Moran's index value runs from +1.0 to -1.0 . Values closest to +1.0 indicate clustering, and those closest to -1.0 indicate dispersion. The $Z$-score produced is a measure of standard deviation; therefore, very large or very small (negative) $Z$-scores indicate that the values are in the tails of the distribution, making the pattern unlikely to be random.

Where Moran's index indicated gross non-random distribution, Hot Spot analysis (ArcGIS ArcInfo Build 2800; ESRI) was used to delineate non-random capture distributions (i.e. 'hot' - and 'coldspots') among trawling events. Each trawling event had an associated start location coordinate pair (i.e. latitude and longitude) and total loggerhead sea turtle captures per unit effort (CPUE), where effort was defined as total trawling effort in minutes. The first step was to run the Incremental Spatial Autocorrelation tool, which measured spatial autocorrelation at set intervals. The tool was used for each trawling sub-region to determine the distance $(\mathrm{km})$ at which the $Z$-score peaked. With a beginning distance of $0.5 \mathrm{~km}$ and a distance increment of $0.25 \mathrm{~km}, Z$-scores peaked at $1.5 \mathrm{~km}$ (Sub-region 1), $3.25 \mathrm{~km}$ (Sub-region 2), $3.5 \mathrm{~km}$ (Sub-region 3), and $4.25 \mathrm{~km}$ (Sub-region 4). We caution, however, that these distances were unique to this survey area and that this procedure, rather than the absolute distance thresholds, should be used for other data sets. These fixed distance bands, and a minimum of 8 respective neighboring trawling events, were then fed into the Generate Spatial Weights Matrix tool. The outputs from this tool (.swm files) were fed into the Conceptualization of Spatial Relationships (Get_Spatial_Weights_From_File) field for the next tool, Spatial Autocorrelation (Moran's I). Significant hot- and coldspots in trawl locations and CPUE were identified using the Getis-Ord Gi statistic $(p<0.05)$. Five trawling events $(0.1 \%)$ in Sub-region 1 were excluded from all analyses due to lack of sufficient neighbors or aberrant CPUE values resulting from insufficient trawl durations.

\section{Serial correlation in capture frequency}

The second null hypothesis of no difference in capture frequency based on presence or absence of loggerhead sea turtles in the previous trawling event was statistically tested $(\alpha=0.05)$ using Chi-squared analysis (Minitab $15^{\mathrm{TM}}$; Minitab) or, where expected values were $<5$, with 2-tailed Fisher's exact tests (http://faculty.vassar.edu/lowry/fisher.html). These statistical tests were performed for the overall data set, as well as with the data partitioned among trawl- 
ing events associated with hotspots, coldspots, and where spatial clustering was not noted. Capture and recapture locations for loggerhead sea turtles with respect to position within or outside of spatial clusters were tested with a 2-tailed Fisher's exact test.

\section{Demographic influences on spatial distribution}

Non-parametric Kruskal-Wallis tests (Minitab 15 ${ }^{\mathrm{TM}}$ ) were used to statistically test for differences in the size $\left(\mathrm{SCL}_{\min }\right)$ distribution of loggerhead sea turtles with respect to latitudinal increments of $0.5^{\circ} \mathrm{N}$ and distance from shore at $4 \mathrm{~km}$ increments. Chi-squared analysis was used to test for differences in the distribution of loggerhead sea turtles $\leq 79.9$ and $\geq 80.0 \mathrm{~cm}$ $\mathrm{SCL}_{\text {min }}$ captured in trawling events associated (vs. not associated) with spatial clusters. Chi-squared analyses were also used to test for differences in the distribution of female and male loggerhead sea turtles, as well as differences in the relative frequencies of mtDNA haplotypes with respect to latitude, distance from shore, and spatially clustered trawling events.

\section{Evaluation of attributes among spatial and non-spatial clusters}

Two hierarchical cluster analyses (single linkage, Euclidean distance) were performed in Minitab $15^{\mathrm{TM}}$ to quantitatively (i.e. percent similarity) compare a suite of attributes among trawling events characterized as coldspots (0), non-spatial clustering locations (1), and hotspots (2). In order to reduce bias associated with unequal observation data, input data for cluster analyses was standardized to 4 descriptive metrics (mean, SD, minimum, and maximum values) for each of the 3 spatial classifications. The first cluster analysis compared the distributions of 53 fish and invertebrate groupings recorded for trawling events (in Supplement 1 at www.int-res.com/ articles/suppl/n018p219_supp.pdf) associated with coldspots, non-spatial clusters, and hotspots. The second cluster analysis compared the distribution of 25 temporal, spatial, and environmental attributes among coldspots, non-spatial clusters, and hotspots. Attributes for the second cluster analysis were previously used to evaluate catch rates for a sub-set of loggerhead sea turtles reported in this study (Arendt et al. 2012c), and are recapped in Supplement 2 at www.int-res.com/articles/suppl/n018p219 _supp.pdf.

\section{RESULTS}

A total of 1461 loggerhead sea turtles Caretta caretta was captured during 4756 trawling events conducted in coastal waters from Winyah Bay to St. Augustine from 2000 to 2003 and 2008 to 2011.

Loggerhead sea turtles were captured in $23 \%$ of trawling events (1081), with $75 \%$ of these positive capture events (815) associated with the capture of 1 loggerhead sea turtle only. Two loggerhead sea turtles were captured in the same trawling event 208 times $(4 \%)$, and the capture of between 3 and upwards to 10 loggerhead sea turtles only occurred 58 times $(1 \%)$.

Only 25 (2\%) loggerhead sea turtles were recaptured during this survey, and were taken (trawl midpoints) $4.6 \pm 6.2 \mathrm{~km}$ (mean $\pm \mathrm{SD}$ ) from where they were originally captured $3.2 \pm 3.3$ years earlier.

Loggerhead capture locations were not randomly distributed within the overall sampling region (Moran's index $=0.08, Z_{4750}=24.0, p<0.001$; Fig. 1) nor within any of 4 sub-regions (Fig. 2A-D): Winyah Bay to Charleston (Moran's index $=0.03$, $\left.Z_{1027}=2.5, \mathrm{p}=0.014\right)$, Charleston to Savannah (Moran's index $=0.02, Z_{1243}=4.0, \mathrm{p}<0.001$ ), Savannah to Brunswick (Moran's index $=0.08$, $\left.Z_{1324}=11.1, \mathrm{p}<0.001\right) ;$ and Brunswick to St. Augustine (Moran's index $=0.08, Z_{1153}=12.5, \mathrm{p}<$ $0.001)$. Nine percent of trawling events (446) were identified as hotspots and accounted for $23 \%$ of loggerhead sea turtle captures (339). Four percent of trawling events (193) were identified as coldspots and accounted for $1 \%$ of loggerhead sea turtle captures (18).

Loggerhead sea turtle capture frequencies reflected spatial clustering; however, limited loggerhead recapture data did not. A significant difference $\left(\chi_{2}^{2}=151.3, p<0.001\right)$ was detected in the proportion of trawling events that captured at least 1 loggerhead sea turtle between hotspots (199 of 446 events, $45 \%$ ), coldspots (16 of 193 events, $8 \%$ ), and locations not associated with spatial clusters (866 of 4117 events, $21 \%$ ). In contrast, among 25 recaptured loggerhead sea turtles, 8 were originally captured in hotspots and 17 were captured elsewhere. Fifty percent (4 of 8) of loggerhead sea turtles originally captured in hotspots were subsequently recaptured in hotspots, and $88 \%$ (15 of 17) of loggerhead sea turtles originally captured at locations other than hotspots were subsequently recaptured at locations other than hotspots. No statistical difference was detected (Fisher's exact test, $\mathrm{p}=0.059$ ) between the proportions of logger- 

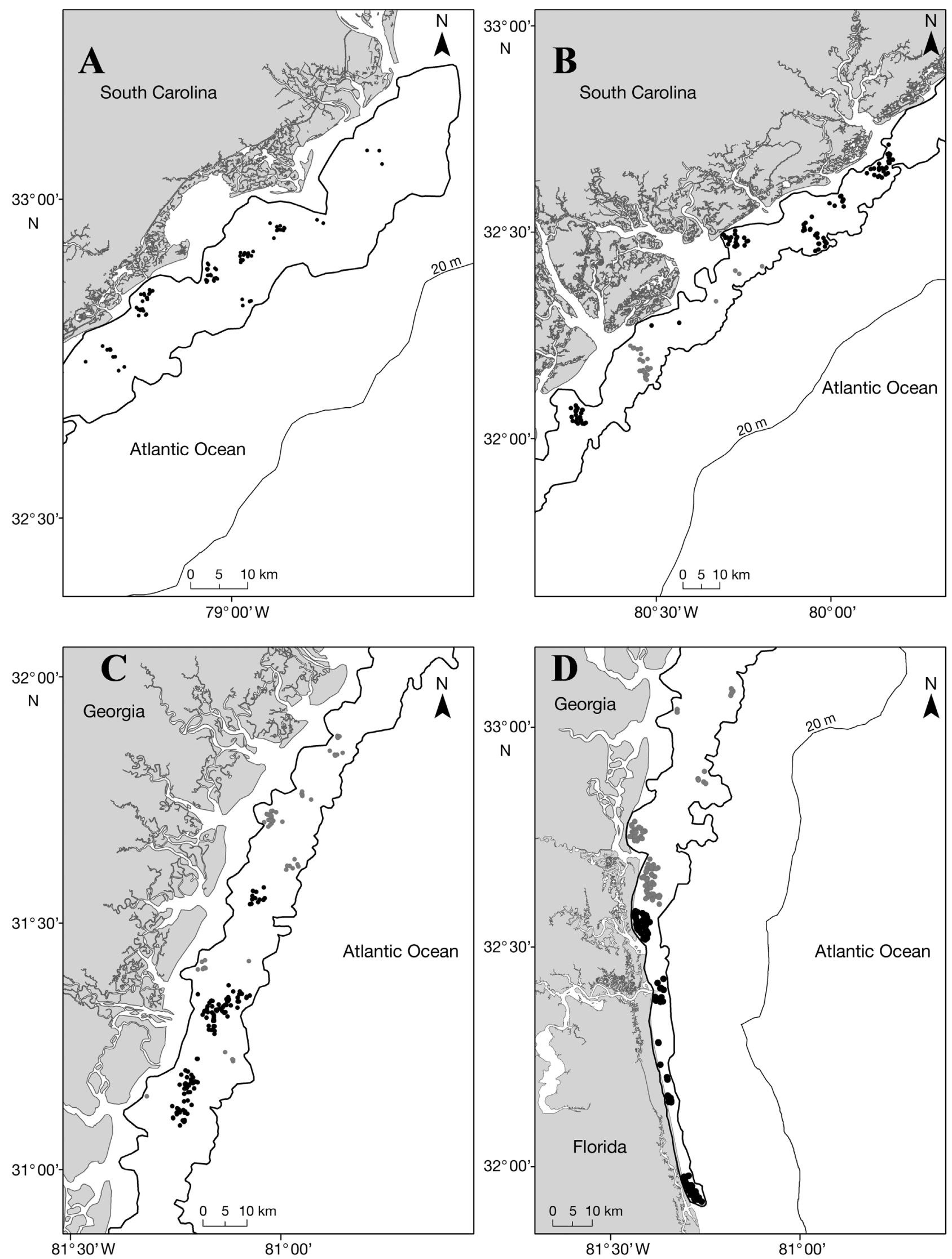
Fig. 2. Caretta caretta. Spatial distribution of loggerhead sea turtle hotspots $(\bullet)$ and coldspots $(\bullet)$, determined by hotspot analysis, in 4 geographic sub-regions: (A) Winyah Bay to Charleston, South Carolina; (B) Savannah, Georgia, to Charleston; (C) Brunswick, Georgia, to Savannah; and (D) St. Augustine, Florida, to Brunswick. Thick black line: trawl survey boundary; thin black line: $20 \mathrm{~m}$ depth contour (out of the field of view in $(\mathrm{C})$

head sea turtles recaptured (1) in or (2) out of a hotspot with respect to capture origin.

Significantly greater capture probability in a consecutive trawl was noted if a loggerhead sea turtle was captured in the preceding trawling event than if it was not, for the overall data set and for hotspots and non-clustered locations; however, this was not observed for coldspots (Table 1).

Overall, loggerhead sea turtles were captured in $28 \%$ of trawling events (258 of 916) when capture had been noted for the preceding event, but only in $21 \%$ of trawling events (706 of 3314) when there had been no capture in the preceding event. Within hotspots, loggerhead sea turtles were captured in $53 \%$ of trawling events (61 of 115) when capture had been noted for the preceding event, but only in $41 \%$ of trawling events (117 of 285) when there had been no capture in the preceding event. For trawling events not associated with spatial clusters, capture in the preceding event was associated with a $25 \%$ (195 of 778 events) capture rate in the subsequent event versus a $20 \%$ (578 of 2882 events) capture rate when there had been no capture in the preceding event. Capture of loggerhead sea turtles in trawling events associated with coldspots only occurred $8 \%$ of the time (13 of 170 events) and were not significantly improved by serial capture correlation.

Table 1. Caretta caretta. Probability of capture and serial capture correlation statistics for loggerhead sea turtles captured (or not captured) landed by research trawling in coastal waters between Winyah Bay, South Carolina, and St. Augustine, Florida, USA, from 2000 to 2003 and 2008 to 2011

\begin{tabular}{|lcccccccc|}
\hline Data set & $\begin{array}{c}\text { Preceding } \\
\text { trawl }\end{array}$ & $\begin{array}{c}\text { Subsequent trawl } \\
\text { Present }\end{array}$ & $\begin{array}{c}\text { Capsent } \\
\text { prob. }\end{array}$ & $\begin{array}{c}\text { Statistical df } \\
\text { test }\end{array}$ & p-value \\
\hline Overall & Absent & 706 & 2608 & 0.21 & $\chi^{2}=19.206$ & 1 & $<0.001$ \\
& Present & 258 & 658 & 0.28 & & & \\
No cluster & Absent & 578 & 2304 & 0.20 & $\chi^{2}=9.225$ & 1 & 0.002 \\
& Present & 195 & 583 & 0.25 & & & \\
Hotspot & Absent & 117 & 168 & 0.41 & $\chi^{2}=4.77$ & 1 & 0.029 \\
& Present & 61 & 54 & 0.53 & & & \\
& Absent & 11 & 136 & 0.07 & Fisher's & 1 & 1.000 \\
& Present & 2 & 21 & 0.09 & & & \\
\hline
\end{tabular}

Loggerhead sea turtles were not randomly distributed with respect to carapace length. Loggerhead sea turtles ranged in size from 44.8 to $103.5 \mathrm{~cm}$ $\mathrm{SCL}_{\min }$, but $91 \%$ (1333) measured $\leq 80.0 \mathrm{~cm} \mathrm{SCL}$ min. Loggerhead size distributions were significantly different among latitudes $\left(H_{7}=116.9\right.$, p <0.001), with larger median sizes correlated $\left(\mathrm{r}^{2}=0.89\right)$ with higher latitudes (Fig. 3A). Loggerhead size distributions were also significantly different with respect to distance from shore $\left(H_{4}=78.5, \mathrm{p}<0.001\right)$, with smallest median sizes correlated $\left(\mathrm{r}^{2}=0.52\right)$ with closest distribution to shore (Fig. 3B). Loggerhead size distributions were not significantly different $\left(\chi_{1}^{2}=0.1, p=0.767\right)$, between hotspots and other trawling events.

Determination of sex and genetic haplotype was possible for 1349 (92\%) and 1385 (95\%) of loggerhead sea turtle captures, respectively. Overall sex ratio was 2.1 (920 females, 429 males) and was not significantly different with respect to latitude $\left(\chi^{2}{ }_{7}=\right.$ 5.7, $\mathrm{p}=0.570)$, distance from shore $\left(\chi^{2}{ }_{4}=3.0, \mathrm{p}=\right.$ $0.554)$, or spatial clustering $\left(\chi_{1}^{2}=0.6, p=0.447\right)$. Overall genetic haplotype distribution was 52\% (721) CC-A01, $37 \%$ (517) CC-A02, and $11 \%$ (147) other haplotypes, including 18 previously described and 5 un-described haplotypes (Table 2). The frequency of occurrence of CC-A01, CC-A02, and aggregated 'other' haplotypes was not significantly different with respect to latitude $\left(\chi^{2}{ }_{14}=8.5, \mathrm{p}=0.864\right)$, distance from shore $\left(\chi_{8}^{2}=10.9, \mathrm{p}=0.206\right)$, or spatial clustering $\left(\chi_{2}^{2}=2.6, \mathrm{p}=0.278\right)$.

Strong associations ( $\geq 96 \%$ similarity) were noted between several fish and invertebrate bycatch groupings (Fig. 4A) and other trawling event attributes (Fig. 4B), but none of these parameters were useful for distinguishing among coldspots, non-spatial clusters, or hotspots. Trawling event classifications were not statistically associated with 53 bycatch groupings until the final step (68\% similarity) of the second hierarchical cluster analysis between trawling event classifications and bycatch groupings. Similarly, trawling event classifications (i.e. coldspot, non-cluster, hotspot) were not statistically associated with 25 temporal, spatial, or environmental attributes until the final step (52\% similarity) of the first hierarchical cluster analysis between trawling event classification and these attributes. 


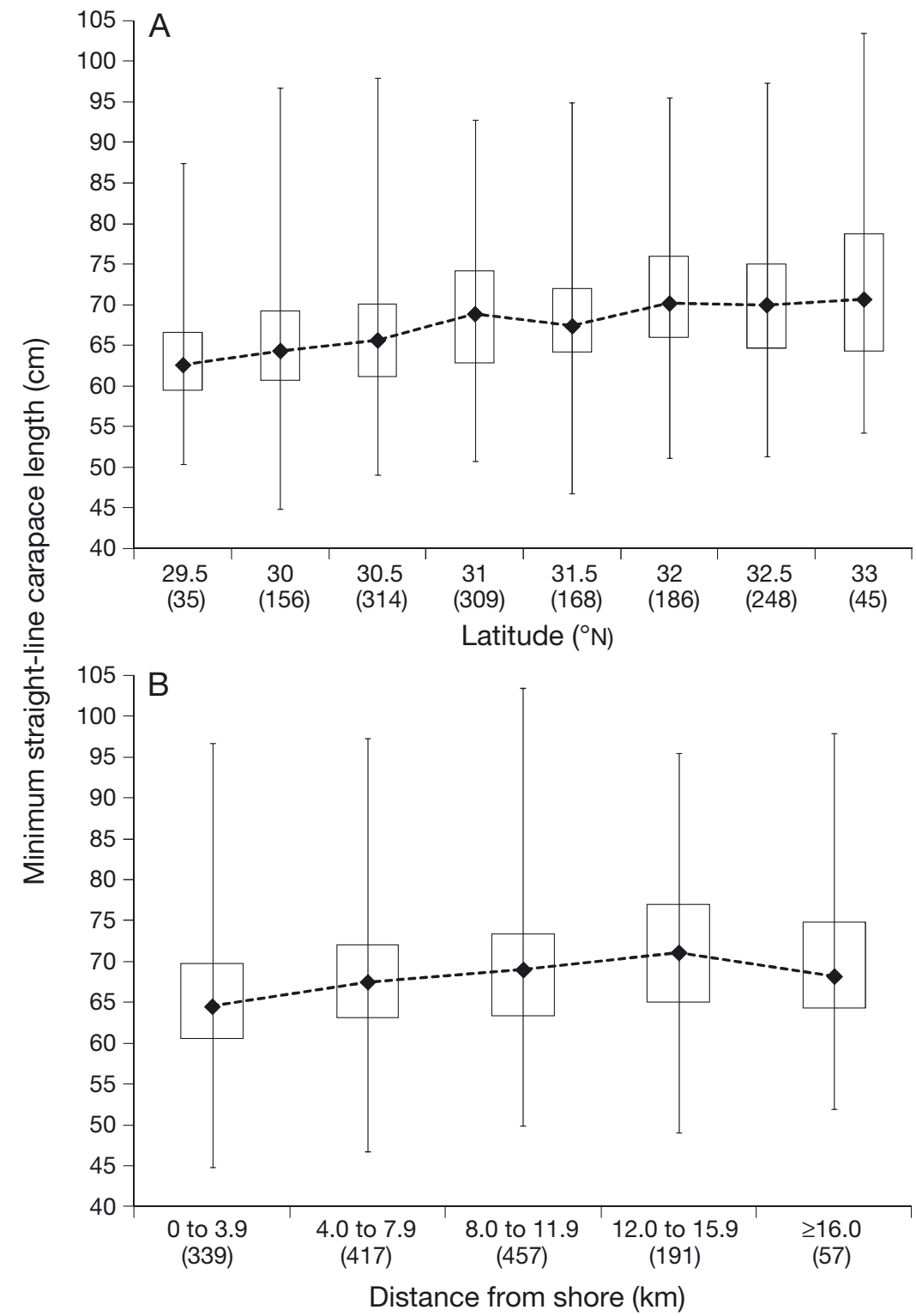

Fig. 3. Caretta caretta. Size distribution (minimum straight-line carapace length, cm) of 1461 loggerhead sea turtles captured between Winyah Bay, South Carolina, and St. Augustine, Florida, USA, from 2000 to 2003 and 2008 to 2011 with respect to $(\mathrm{A})$ latitude $\left({ }^{\circ} \mathrm{N}\right)$ and $(\mathrm{B})$ distance from shore $(\mathrm{km})$. Median size: black diamond; inter-quartile range: open box; minimum and maximum values: error bars. The number of loggerhead sea turtles measured in each category appears in parentheses below the category label

the frequency of occurrence of the study subject. Consequently, considerably more is known about the importance of macro-scale than meso-scale influences. For example, thermal tolerance ranges for loggerhead sea turtles Caretta caretta have been known for some time (Epperly et al. 1995, Coles \& Musick 2000), but considerably less is known about the possible role of temperature as a driver of localized distribution patterns within preferred temperature ranges. However, Ferreira et al. (2011) recently reported a significant temperature influence for oceanic loggerhead sea turtles within a narrow temperature range $\left(18\right.$ to $\left.23^{\circ} \mathrm{C}\right)$. Consequently, meso-scale feature influences should not be presumed to be inconsequential. As emphasized by the present study, meso-scale considerations also include fine-scale spatial distributions within established geographic ranges during periods of temporal occurrence.

Loggerhead sea turtles were captured throughout the survey area, where they were not, however, randomly distributed. Nearly one-quarter of all loggerhead sea turtles were captured in $<10 \%$ of the survey area in spatially concentrated hotspots where the capture probability was 2 to 5 times greater than elsewhere in the survey area. Significant serial correlation in capture probability was also noted at all locations except for coldspots, such that the relative probability of capture increased by onequarter to one-third if a loggerhead sea turtle had been captured in the previous trawling event. Tagged loggerhead sea turtles were also predominantly recaptured within $10 \mathrm{~km}$ of where they were originally captured

\section{DISCUSSION}

Illumination of intrinsic influences on the distribution of highly migratory species such as sea turtles is essential to their effective conservation and management. The ability to isolate the importance of any parameter requires sufficient variability in both the observed measurements for that parameter and in up to several years earlier. As such, these observations collectively suggest that, although loggerhead sea turtles are widely distributed in coastal areas throughout this region (Arendt et al. 2012b), in-water surveys to monitor relative abundance trends (Arendt et al. 2012c) should employ random sampling to minimize biased sampling of areas of exceptionally high or low abundance. This suggestion also 
Table 2. Caretta caretta. Frequency of occurrence of genetic haplotypes carried by loggerhead sea turtles captured in a coastal trawl survey between Winyah Bay, South Carolina, and St. Augustine, Florida, USA, from 2000 to 2003 and 2008 to 2011

\begin{tabular}{|c|c|c|c|}
\hline Haplotype & Occurrences & Haplotype & Occurrences \\
\hline CC-A01 & 721 & CC-A20 & 10 \\
\hline CC-A02 & 517 & CC-A21 & 2 \\
\hline CC-A03 & 49 & CC-A36 & 1 \\
\hline CC-A04 & 2 & CC-A37 & 2 \\
\hline CC-A05 & 4 & CC-A40 & 1 \\
\hline CC-A07 & 11 & CC-A43 & 3 \\
\hline CC-A08 & 1 & CC-A44 & 1 \\
\hline CC-A09 & 9 & CC-A46 & 1 \\
\hline CC-A10 & 7 & CC-A49 & 1 \\
\hline CC-A13 & 3 & & \\
\hline CC-A14 & 34 & New & 5 \\
\hline
\end{tabular}

applies to shipboard visual surveys (Griffin \& Griffin 2003), which are also prone to spatial artifacts, but may not be an equally important consideration for aerial surveys, which rapidly sample vast tracts in short order and are therefore considered less susceptible to position effects (Epperly et al. 1995).

Localized spatial distribution by loggerhead sea turtles in neritic habitats has previously been reported; however, the data in the present study are novel due to the fine-scale spatial resolution over which replicate observations of spatial clustering were recorded. Spatial clustering was observed at scales of $<5 \mathrm{~km}$, approximately twice the linear transect length of the trawling events in which loggerhead sea turtles were captured in the present study. Site fidelity at this scale has only previously been reported for loggerhead sea turtles foraging in estuarine habitats (Byles 1988, Avens et al. 2003); however, these observations occurred during brief temporal windows. Satellite telemetry has documented localized detection of loggerhead sea turtles in marine habitats, often in areas coinciding with clustered commercial fishing efforts, on numerous continental shelves (Peckham et al. 2007, Cardona et al. 2009, Mangel et al. 2011, Arendt et al. 2012b). However, even when free-ranging sea turtles are detected by satellite telemetry over large spatial areas, telemetry-derived spatial clusters also tend to be spatially limited relative to the total area occupied, but temporally inclusive of overall detection events.

As noted by Zhang et al. (2005), the necessity of adjustments for temporal autocorrelation has been appreciated for several decades, but accounting for spatial influences on capture rates has only recently become commonplace. Despite being a relatively straight-forward metric to compute, as evidenced by the present study, few published data sets have shown the influence of spatial clustering on sea turtle captures. Pons et al. (2010) delineated spatial areas based on capture rates as well as latitude in their analysis of sea turtle capture data in South Atlantic longline fisheries, representing one of the few sea turtle studies where spatial area use was considered as an analytical model term. However, due to a nearly 8-fold change in annual catch levels among years, spatial clustering was relegated to the second most important model term in the Pons et al. (2010) study. In another study conducted in pelagic habitats, loggerhead capture probability was most closely aligned with distance from shore, superseding even fishing effort as the most important model term (Báez et al. 2007). However, mixed results regarding spatial influences on capture rates have been reported for neritic habitats. In an analysis of sea turtle interaction rates with trawl and dredge fisheries off the central portion of the east coast of the USA, Warden (2011) reported latitude to account for the greatest proportion of explained data set deviance. Conversely, in a companion study conducted during a similar spatiotemporal window, Murray (2011) reported sea-surface temperature to be the most important model term.

We also caution that not all data sets will necessarily benefit from including spatial correction terms in the analytical model and that the potential for benefiting is likely a function of the extent to which the underlying source data set is zero dispersed. For example, in a severely (i.e. $99 \%$ ) zero-dispersed data set, Winter et al. (2011) noted that sea-bird bycatch modeled using a generalized linear model without a spatial adjustment factor consistently performed better than models in which spatial autocorrelation terms were considered. This finding was contrary to greatly improved model performance for yellowfin tuna Thunnus albacares captures when they were modeled in the context of spatial and other habitat considerations (Nishida \& Chen 2004). Incidentally, Nishida \& Chen (2004) included a constant as a model term specifically 'to mitigate the problem of zero catch', and all relative index values that they reported were $>2$. Therefore, we surmise that, although numerous analytical models can handle zero-laden data sets (Maunder \& Punt 2004), their performance still ultimately rests with the extent of variance within any given data set.

Given site fidelity documented by telemetry (Avens et al. 2003, Arendt et al. 2012b) and suggested by recapture events in the present study, it is 

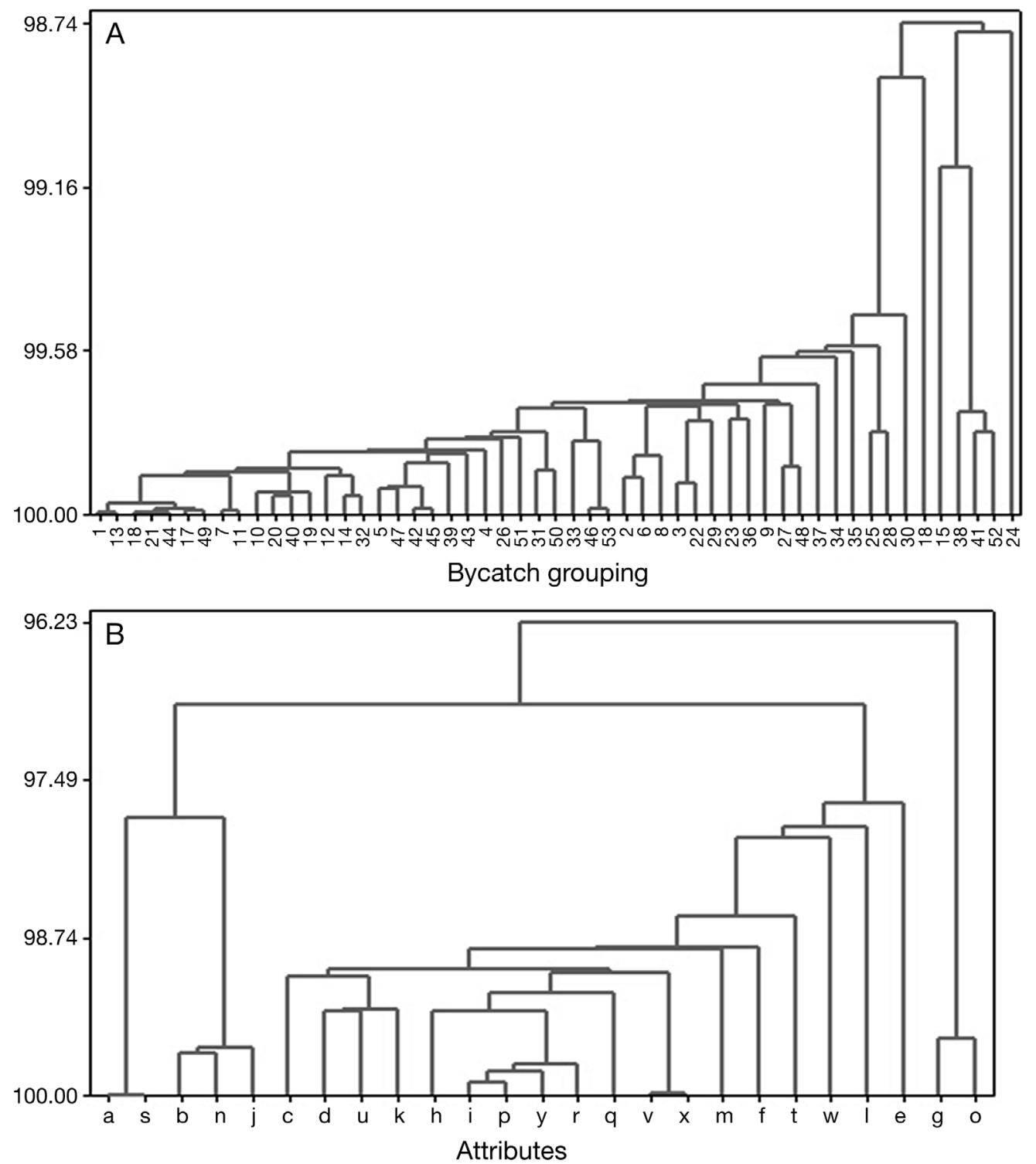

Fig. 4. Caretta caretta. Percent similarity between (A) fish and invertebrate bycatch and (B) temporal, spatial, and environmental attributes among trawling events classified as coldspots, non-spatial clusters, and hotspots. Numbers (A) and letters (B) on the $x$-axis correspond to data presented in Tables S1 \& S2, respectively, in the supplement; www.int-res.com/articles/ suppl/n018p219_supp.pdf. Trawling event classifications were associated with parameters in the final step of cluster analyses with (A) $68 \%$ and (B) $52 \%$ similarity (not shown)

surprising that spatial clustering did not encompass $>9 \%$ of trawling events or account for $>23 \%$ of sea turtle captures. One possible explanation for this result is that the prevalence of non-capture or singleturtle-only-capture events did not permit a complete delineation of the spatial extent of the observed clusters. This suggestion is supported by the observation that a small $\left(30 \mathrm{~km}^{2}\right)$ hotspot located to the southeast of Charleston $\left(32.7^{\circ} \mathrm{N}\right)$ in the present study was completely encompassed within (J. Boynton pers. obs.) a larger $\left(568 \mathrm{~km}^{2}\right)$ hotspot where satellite-tagged juve- nile loggerhead sea turtles were detected $59 \%$ of the time between spring and autumn (Arendt et al. 2012b). Relative to the present study, the hotspot identified by Arendt et al. (2012b) was generated from a more geographically dispersed data set (i.e. Zscore peak of 8 km; J. Boynton pers. obs.). Furthermore, the observation values analyzed by Arendt et al. (2012b) reflected a greater overall range in magnitude (i.e. $\leq 45$ detections per 1-min grid) than reported in the present study where $\leq 10$ loggerhead sea turtles were captured per trawling event. We 
attribute the discrepant findings between these 2 studies conducted in the same geographic area to the fact that satellite-tagged sea turtles were free to be detected anywhere, whereas, in the present study, sampling events occurred over a more discrete area. Given modest (i.e. a factor of 2) differences in Z-score peak distances and input observation sample size between the present study and that of Arendt et al. (2012b), a 20-fold difference in hotspot area measurements between these 2 studies reinforces the link between input data variability and hotspot area calculations. Nevertheless, where limited variability is noted, we also suggest that even conservative estimates are better than no estimates of spatial clustering when assessing trends in sea turtle captures.

Perhaps, owing to the conservative assignment of trawling events to spatial clusters, cluster attributes were not discerned with respect to a plethora of parameters examined for that purpose. However, the lack of definitive traits associated with spatial clusters in the present study also suggests relative homogeneity with respect to sampling conditions throughout the survey area. Particularly noteworthy was the general lack of clustering with respect to loggerhead sea turtle demographic parameters, which exhibited distributions similar to those reported in other inwater surveys in the SE USA (Wibbels et al. 1991, Bowen et al. 2004, Braun-McNeill et al. 2007). Uniformity in demographic distributions, particularly for sex and genetic ratios, suggests that loggerhead sea turtles captured in the present study comprise part of a regional stock; thus, at a minimum, the spatial use patterns reported here are likely applicable elsewhere in the region.

The general latitudinal cline with respect to larger size distributions further north within the survey area roughly corresponds to the epicenter of loggerhead sea turtle nesting in the Northern Recovery Unit (NRU) off South Carolina (NMFS/USFWS 2008). The generally larger size distribution of loggerhead sea turtles captured in this trawl survey compared to those captured in pound net surveys in North Carolina (Epperly et al. 2007) was also consistent with the suggestion by Hopkins-Murphy et al. (2003) of a developmental movement south along the US east coast and into the southeastern Gulf of Mexico. The slight increase in turtle size with distance from shore was also consistent with the observation by HopkinsMurphy et al. (2003) that the largest immature loggerhead sea turtles are found in open shelf waters, which may reflect greater lung volume in larger turtles and subsequent greater maximum depth of lungcontrolled neutral buoyancy (Hays et al. 2004). Con- sequently, the latitudinal and longitudinal clines reported herein substantiate the need to conduct inwater sea turtle surveys across broad geographic expanses.

Given the inability to explain the origin of spatial clusters in the context of biotic and other environmental parameters, future endeavors to elucidate the nature of spatial clusters should also consider gear efficiency and, ultimately, sea turtle catchability. To date, only a handful of studies have reported on factors which may indirectly affect gear and capture efficiency, such as fishing vessel characteristics (Pons et al. 2010) or gear configuration (Pradhan \& Leung 2006, Murray 2011, Warden 2011). In the present study, only 1 directly corresponding metric (i.e. vessel towing speed) was considered, and this metric was associated with a nominal standard deviation. However, because the efficiency of gear operation in the present study was not known, the extent to which even slight deviations in vessel towing speed may influence gear efficiency is not known either (Weinberg et al. 2002). Because sea turtles can actively evade trawling gear (Ogren et al. 1977), it is especially important to determine the extent to which gear efficiency remains constant, particularly given that trawling may be conducted with, against, or across tidal currents, as well as over smooth versus rough seafloor. Assessment of gear efficiency under various sampling conditions could be directly determined with net mensuration gear which is routinely used in fisheries research (Weinberg et al. 2002). Assessment of catchability using gear-dependent means (Butler et al. 1987) is not recommended, however, given the uncertainty regarding constant gear efficiency and the inability to distinguish between gear avoidance and a turtle simply not being present in the path of an approaching trawl to begin with.

Similarity in loggerhead sea turtle capture distributions across geographically diverse and globally dispersed foraging habitats suggests that the spatial distribution patterns and recommendations reported herein are applicable throughout this species' distribution range. Numerous methods (i.e. generalized additive, generalized linear, delta 2-step) used to analyze zero-laden capture data fit to several distributions (i.e. Poisson, negative binomial, log-normal) have rarely accounted for more than half of data set deviance (Pons et al. 2010, Murray 2011, Warden 2011, Arendt et al. 2012a). Given the reliance on Akaike's information criterion scores to select the most appropriate model for these data sets, low explanation of variance does not likely reflect statistical technique. Generally consistent results among 
studies also reinforce the need to consider additional parameters if greater amounts of deviance are to be explained. We reiterate that a high priority should be placed on analyzing in-water data sets in the context of spatial considerations and gear efficiency, particularly given the historic emphasis on expanded analysis of such data sets collected from a network of study sites for future management of sea turtles (NMFS/ USFWS 2008).

Acknowledgements. We thank B. Stender, R. Vendetti, P. Maier, and L. Ligouri for valuable program support. Numerous captains and crews, seasonal staff, and volunteers provided invaluable and tireless support in the field. Funding was provided by NOAA Fisheries grants NA97FL0375, NA07FL0499, NA03NMF4720281, and NA08NMF4720502. Research was authorized under Section 10(a)(1)(A) permits (Nos. 1245, 1540, 15566), a GADNR permits (Nos. 1141, 21303), and FWC permits (Nos. 140, 163). This is Contribution 696 from the South Carolina Department of Natural Resources and Contribution 389 from the Grice Marine Biology Laboratory.

\section{LITERATURE CITED}

Alfaro Shigueto J, Mangel JC, Seminoff JA, Dutton PH (2008) Demography of loggerhead turtles Caretta caretta in the southeastern Pacific Ocean: fisheries-based observations and implications for management. Endang Species Res 5:129-135

Anderson DR (2001) The need to get the basics right in wildlife field studies. Wildl Soc Bull 29:1294-1297

Arendt MD, Schwenter JA, Segars AL, Byrd JI and others (2012a) Catch rates and demographics of loggerhead sea turtles (Caretta caretta) captured from the Charleston, South Carolina, shipping channel during the period of mandatory use of turtle excluder devices (TEDs). Fish Bull 110:98-109

Arendt MD, Segars AL, Byrd JI, Boynton J and others (2012b) Seasonal distribution patterns of juvenile loggerhead sea turtles (Caretta caretta) following capture from a shipping channel in the Northwest Atlantic Ocean. Mar Biol 159:127-139

Arendt MD, Schwenter JA, Segars AL, Byrd JI, Whitaker JD, Parker L (2012c) Temporal trends (2000-2011) and influences on fishery-independent catch rates for loggerhead sea turtles (Caretta caretta) at an important coastal foraging region of the Southeast U.S. Fish Bull 110(4): $470-483$

Avens L, Braun-McNeill J, Epperly S, Lohmann KJ (2003) Site fidelity and homing behavior in juvenile loggerhead sea turtles (Caretta caretta). Mar Biol 143:211-220

> Báez JC, Real R, García-Soto C, de la Serna JM, Macías D, Camiñas JA (2007) Loggerhead turtle by-catch depends on distance to the coast, independent of fishing effort: implications for conservation and fisheries management. Mar Ecol Prog Ser 338:249-256

- Bowen BW, Bass AL, Chow SM, Bostrom M and others (2004) Natal homing in juvenile loggerhead turtles (Caretta caretta). Mol Ecol 13:3797-3808

> Braun-McNeill J, Epperly SP, Owens DW, Avens L, Williams E, Harms CA (2007) Seasonal reliability of testosterone radioimmunoassay (RIA) for predicting sex ratios of juvenile loggerhead (Caretta caretta) turtles. Herpetologica 63:275-284

Butler RW, Nelson WA, Henwood TA (1987) A trawl survey method for estimating loggerhead turtle, Caretta caretta, abundance in five eastern Florida channels and inlets. Fish Bull 85:447-453

Byles RA (1988) Behavior and ecology of sea turtles from Chesapeake Bay, Virginia. PhD dissertation, School of Marine Science, College of William and Mary/Virginia Institute of Marine Science, Gloucester Point, VA

> Cardona L, Revelles M, Parga ML, Tomás J and others (2009) Habitat use by loggerhead sea turtles Caretta caretta off the coast of eastern Spain results in a high vulnerability to neritic fishing gear. Mar Biol 156:2621-2630

Coles WC, Musick JA (2000) Satellite sea surface temperature analysis and correlation with sea turtle distribution off North Carolina. Copeia 2000:551-554

Crouse DT, Crowder LB, Caswell H (1987) A stage-based population model for loggerhead sea turtles and implications for conservation. Ecology 68:1412-1423

> Crowder LB, Crouse DT, Heppell SS, Martin TH (1994) Predicting the impact of turtle excluder devices on loggerhead sea turtle populations. Ecol Appl 4:437-445

Ehrhart LM, Redfoot WE, Bagley DA (2007) Marine turtles of the central region of the Indian River Lagoon System, Florida. Fla Sci 70:415-434

Epperly SP, Braun J, Chester AJ (1995) Aerial surveys for sea turtles in North Carolina inshore waters. Fish Bull 93: 254-261

Epperly SP, Braun-McNeill J, Richards PM (2007) Trends in catch rates of sea turtles in North Carolina, USA. Endang Species Res 3:283-293

Ferreira RL, Martins HR, Bolten AB, Santos MA, Erzini K (2011) Influence of environmental and fishery parameters on loggerhead sea turtle by-catch in the longline fishery in the Azores archipelago and implications for conservation. J Mar Biol Assoc UK 91:1697-1705

Forcada J, Aguilar A, Hammond PS, Pastor X, Aguilar R (1994) Distribution and numbers of striped dolphins in the western Mediterranean Sea after the 1990 epizootic outbreak. Mar Mamm Sci 10:137-150

- Frazer NB (1992) Sea turtle conservation and halfway technology. Conserv Biol 6:179-184

> Gardner B, Sullivan PJ, Morreale SJ, Epperly SP (2008) Spatial and temporal statistical analysis of bycatch data: patterns of sea turtle bycatch in the North Atlantic. Can J Aquat Sci 65:2461-2470

Gilman E, Kobayashi D, Swenarton T, Brothers N, Dalzell P, Kinan-Kelly I (2007) Reducing sea turtle interactions in the Hawaii-based longline swordfish fishery. Biol Conserv 139:19-28

Griffin RB, Griffin NJ (2003) Distribution, habitat partitioning, and abundance of Atlantic spotted dolphins, bottlenose dolphins, and loggerhead sea turtles on the eastern Gulf of Mexico continental shelf. Gulf Mex Sci 2003:23-34

Hays GC, Metcalfe JD, Walne AW (2004) The implications of lung-regulated buoyancy control for dive depth and duration. Ecology 85:1137-1145

> Hill JK, Thomas CD, Blakeley DS (1999) Evolution of flight morphology in a butterfly that has recently expanded its geographic range. Oecologia 121:165-170

Hopkins-Murphy SR, Owens DW, Murphy TM (2003) Ecology of immature loggerheads on foraging grounds and adults in inter-nesting habitat in the eastern United 
States. In: Bolten AB, Witherington BE (eds) Synopsis of the biology and conservation of the loggerhead sea turtle. Smithsonian Institution Press, Washington, DC, p 79-92

Kobayashi DR, Cheng IJ, Parker DM, Polovina JJ, Kamezaki N, Balazs GH (2011) Loggerhead turtle (Caretta caretta) movement off the coast of Taiwan: characterization of a hotspot in the East China Sea and investigation of mesoscale eddies. ICES J Mar Sci 68:707-718

Lewison RL, Soykan CU, Franklin J (2009) Mapping the bycatch seascape: multispecies and multi-scale spatial patterns of fisheries bycatch. Ecol Appl 19:920-930

> Loughlin TR, Rugh DJ, Fiscus CH (1984) Northern sea lion distribution and abundance: 1956-80. J Wildl Manag 48: 729-740

Mangel JC, Alfaro-Shigueto J, Witt MJ, Dutton PH, Seminoff JA, Godley BJ (2011) Post-capture movements of loggerhead turtles in the southeastern Pacific Ocean assessed by satellite tracking. Mar Ecol Prog Ser 433: 261-272

Mansfield KL, Saba VS, Keinath JA, Musick JA (2009) Satellite tracking reveals a dichotomy in migration strategies among juvenile loggerhead turtles in the Northwest Atlantic. Mar Biol 156:2555-2570

> Marcovaldi MA, Chaloupka M (2007) Conservation status of the loggerhead sea turtle in Brazil: an encouraging outlook. Endang Species Res 3:133-143

> Marsh H, Sinclair DF (1989) Correcting for visibility bias in strip transect aerial surveys of aquatic fauna. J Wildl Manag 53:1017-1024

Maunder MN, Punt AE (2004) Standardizing catch and effort data: a review of recent approaches. Fish Res 70: 141-159

Murray KT (2011) Interactions between sea turtles and dredge gear in the U.S. sea scallop (Placopecten magellanicus) fishery, 2001-2008. Fish Res 107:137-146

NMFS/USFWS (National Marine Fisheries Service and U.S. Fish and Wildlife Service) (2008) Recovery plan for the Northwest Atlantic population of the loggerhead sea turtle (Caretta caretta), 2nd rev. National Marine Fisheries Service, Silver Spring, MD

National Research Council (1990) Decline of the sea turtles: causes and prevention. National Academy Press, Washington, DC

Nishida T, Chen DG (2004) Incorporating spatial autocorrelation into the general linear model with an application to the yellowfin tuna (Thunnus albacares) longline CPUE data. Fish Res 70:265-274

Ogren LH, Watson JW, Wickman DA (1977) Loggerhead sea turtles, Caretta caretta, encountering shrimp trawls. Mar Fish Rev 39:15-17

Owens DW, Ruiz GJ (1980) New methods of obtaining blood and cerebrospinal fluid from marine turtles. Herpetologica 36:17-20

Parra GJ, Schick R, Corkerson PJ (2006) Spatial distribution and environmental correlates of Australian snubfin and Indo-Pacific humpback dolphins. Ecography 29:396-406

Peckham SH, Maldonado Diaz D, Walli A, Ruiz G, Crowder LB, Nichols WJ (2007) Small-scale fisheries bycatch jeopardizes endangered Pacific loggerhead turtles. PLoS ONE 2:e1041

Pennington M (1996) Estimating the mean and variance from highly skewed marine data. Fish Bull 94:498-505

Petersen SL, Honig MB, Ryan PG, Nel R, Underhill LG (2009) Turtle bycatch in the pelagic longline fishery off southern Africa. Afr J Mar Sci 31:87-96

> Pons M, Domingo A, Sales G, Fiedler FN, Miller P, Giffoni B, Ortiz M (2010) Standardization of CPUE of loggerhead sea turtle (Caretta caretta) caught by pelagic longliners in the southwestern Atlantic Ocean. Aquat Living Resour 23:65-75

> Pradhan NC, Leung PS (2006) A Poisson and negative binomial regression model of sea turtle interactions in Hawaii's longline fishery. Fish Res 78:309-322

Reed JK (2004) General description of deep-water coral reefs of Florida, Georgia and South Carolina: a summary of current knowledge of the distribution, habitat, and associated fauna. A report to the South Atlantic Fishery Management Council, NOAA/NMFS, Washington, DC. Harbor Branch Oceanographic Institute, Fort Pierce, FL

> Revelles M, Isern-Fontanet J, Cardona L, San Félix M, Carreras C, Aguilar A (2007) Mesoscale eddies, surface circulation and the scale of habitat selection by immature loggerhead sea turtles. J Exp Mar Biol Ecol 347:41-57

> Roberts MA, Anderson CJ, Stender B, Segars A, Whitaker JD, Grady JM, Quattro JM (2005) Estimated contribution of Atlantic coastal loggerhead turtle nesting populations to offshore feeding aggregations. Conserv Genet 6: 133-139

Smith SDA, Simpson RD (1995) Effects of the 'Nella Dan' oil spill on the fauna of Durvillaea Antarctica holdfasts. Mar Ecol Prog Ser 121:73-89

Smith RC, Dustan P, Au D, Baker KS, Dunlap EA (1986) Distribution of cetaceans and sea-surface chlorophyll concentrations in the California Current. Mar Biol 91: 385-402

VanDolah R, Maier P, Sedberry G, Barans C, Idris F, Henry V (1994) Distribution of bottom shelf habitats on the continental shelf off South Carolina and Georgia. Final report Southeast Area Monitoring and Assessment Program South Atlantic Committee, South Carolina Dept of Natural Resource, Charleston, SC

- Wallace BP, Lewison RL, McDonald SL, McDonald RK and others (2010) Global patterns of marine turtle bycatch. Conserv Lett 3:131-142

Warden ML (2011) Modeling loggerhead sea turtle (Caretta caretta) interactions with US mid-Atlantic bottom trawl gear for fish and scallops, 2005-2008. Biol Conserv 144: 2202-2212

> Watson JW, Epperly SP, Shah AK, Foster DG (2005) Fishing methods to reduce sea turtle mortality associated with pelagic longlines. Can J Fish Aquat Sci 62:965-981

- Weinberg KL, Somerton DA, Munro PT (2002) The effect of trawl speed on the footrope capture efficiency of a survey trawl. Fish Res 58:303-313

Wibbels TA, Martin RE, Owens DW, Amoss MSJ Jr (1991) Female-biased sex ratio of immature loggerhead sea turtles inhabiting the Atlantic coastal waters of Florida. Can J Zool 69:2973-2977

Winter A, Jiao Y, Browder JA (2011) Modeling low rates of seabird bycatch in the U.S. Atlantic longline fishery. Waterbirds 34:289-303

- Zhang L, Gove JH, Heath LS (2005) Spatial residual analysis of six modeling techniques. Ecol Model 186:154-177

Submitted: March 6, 2012; Accepted: July 14, 2012

Proofs received from author(s): September 7, 2012 